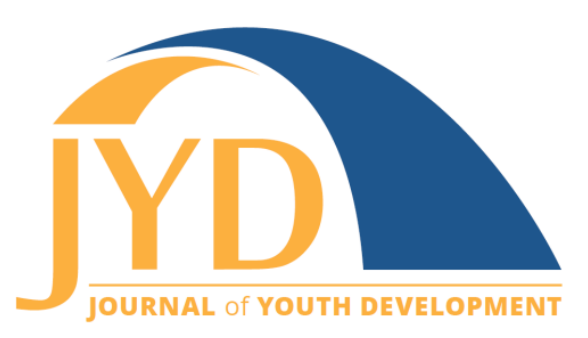

http://jyd. pitt. edu/ | Vol. 14 Issue 1 DOI 10.5195/jyd.2019.739 | ISSN 2325-4017 (online)

\title{
Frontiers in Theory-Predicated Research in Youth Development: A Commentary
}

\author{
Richard M. Lerner \\ Institute for Applied Research in Youth Development, Tufts University \\ richard.lerner@tufts.edu
}

\begin{abstract}
The field of youth development sits at the frontier of new opportunities for research and practice. These opportunities are enabled by innovations in theory and in theory-inspired research methods. Framed by relational developmental systems metatheory, dynamic systems models of youth development emphasize that every young person has the potential to change positively by aligning specific individual strengths and contextual resources that, together, can optimize the life paths of a young person. The methods linked to these theoretical models combine to help identify the specific links between an individual and his or her context that may maximize thriving across the adolescent decade. The evidence derived from theory-predicated use of these methods may be used to create innovations in youth development programs and policies that promote lives of personal thriving and social contribution among the diverse young people of our world.
\end{abstract}

Key words: dynamic systems theory, relational developmental systems metatheory, developmental methodology, idiographic change, specificity principle

The study of youth development is entering a new and important era of theory-predicated methodological innovations and research (e.g., Cantor, Osher, Berg, Steyer \& Rose, 2018; Osher, Cantor, Berg, Steyer, \& Rose, 2018). The field is at the frontier of refining how youth develop within a dynamic system (i.e., an integrated set of mutually-influential relations between a youth and his/her contexts). Such a system may provide opportunities to enhance the life paths of all youth, no matter the instances of diversity they represent. This diversity includes variation in levels of adversity and challenges youth may have experienced in early life. In addition, the field of youth development may provide settings wherein innovations in developmental methodology may be used to test theoretical views about this diversity of developmental pathways and about the potential to promote greater thriving among all youth

(cc) EY New articles in this journal are licensed under a Creative Commons Attribution 4.0 License. This journal is published by the University Library System, University of Pittsburgh and is cosponsored by the University of Pittsburgh Press. The Journal of Youth Development is the official peer-reviewed publication of the National Association of Extension 4-H Agents and the National AfterSchool Association. 
Theory-Predicated Research in Youth Development

through enhancing bidirectional relations with their contexts (e.g., families, schools, and community programs). These methodological innovations involve research designs, measurement, and data analysis.

The purpose of this commentary is to describe these frontiers of theory and methodology in which the study of youth development sits. In addition, I hope this commentary will present a useful vision for how the theoretical and methodological innovations I discuss may frame future contributions to the description, explanation, and optimization of youth development that can be made by members of the field.

\section{On the Frontier of Theoretical Innovation}

Two benchmark articles-by Cantor and colleagues (2018) and by Osher and colleagues (2018) - best capture a profound evolution in thinking about youth development and provide evidence to support actions that enhance the lives of all young people. The two articles, published as companion pieces, integrated findings from several scholarly disciplines, from biology through sociology and history. The research underscores that youth development involves dynamic (i.e., mutually influential; coacting) relations between a young person and the contexts within which he or she lives. These coactions may be represented as youth $\Leftrightarrow$ context relations.

The power of the Cantor et al. and the Osher et al. articles is that they synthesize findings about major constructs involved in the study of human development within a dynamic, developmental systems framework. Cantor et al. (2018) note that many of the theoretical models of individual behavior and development often ask narrow questions (i.e., ones relevant to only specific fields) and involve research that is reductionist and devoid of sensitivity to individual and cultural diversity and historical change (e.g., see Bronfenbrenner \& Morris, 2006, and Elder, Shanahan, \& Jennings, 2015, for comparable critiques).

As a consequence, Cantor et al. (2018) indicate that there is a great need to align and integrate discipline-specific knowledge from biology, neuroscience, psychology, and the social sciences to create (a) a holistic understanding of youth (i.e., one that emphasizes the inseparability of the biological, psychological, and social facets of a person); and, as well, (b) a contextuallysensitive perspective about youth (i.e., one that recognizes the specific family, community, cultural, and physical ecology settings of youth). Cantor et al. explain that, together, holism and 
Theory-Predicated Research in Youth Development

contextual sensitivity allow researchers and practitioners to best understand and promote healthy development and learning for diverse youth.

For instance, using dynamic systems concepts, Cantor et al. (2018) integrate the literatures pertinent to epigenetics and to brain malleability to discuss topics central to the understanding of an individual's development. These topics include skill development and learning, selfregulation, cognitive flexibility, executive functioning, working memory, impacts of stress and adversity on healthy brain development, resilience, social relationships and attachment, and the impacts of the nested systems (i.e., the micro-, meso-, exo-, macro-, and chrono-systems) within the ecology of human development (Bronfenbrenner, 2005; Bronfenbrenner \& Morris, 2006).

Osher et al. (2018) expand the scope of this synthesis by emphasizing the importance of individual $\Leftrightarrow$ context relations as key bases of development. Osher et al. explained how social and cultural contexts may support and/or undermine individual development. They note that, because no two individuals share the same history of individual $\Leftrightarrow$ context relations across life, then, at least in part, each individual's pathway across the life course will be truly idiographic (i.e., specific to a single individual). Osher et al. also explained that these dynamics extend even further to include biology $\Leftrightarrow$ context relations (e.g., gene $\Leftrightarrow$ context relations). As a consequence, the influences between "nature" and "nurture" variables are always mutual. Thus, genetic determination is a myth. Genetic transcription and expression (biology) are always shaped by contextual processes within the dynamic gene $\Leftrightarrow$ context system (e.g., Cole, 2014; Moore, 2015; Richardson, 2017; Slavich \& Cole, 2013).

In other words, Osher et al. (2018) explained that human development is not predetermined or fixed. It is not prefigured in a genetic program. Rather, the timing of specific gene $\Leftrightarrow$ context relations combine so that each person is unique and responsive across the life span to variations in social relationships, culture, and history. In essence, then, Osher et al. (2018) forwarded ideas about the mutually-influential developmental relations between a young person and the ecology of human development that have also been made by Bronfenbrenner (e.g., 2005; Bronfenbrenner \& Morris, 2006), Elder (e.g., 1998; Elder, et al., 2015), and Overton, (2015).

Of course, this potential for change is not always a "good" thing. Plasticity (the potential for systematic change across life) that results from the dynamic relations between the individual and his/her context can have both positive influences on the development of a young person or 
Theory-Predicated Research in Youth Development

deleterious influences on him or her-due to, for instance poverty, racism, sexism, bullying, chronic stress, violence, and educational and health disparities (see also, Geldhof et al., 2019). Thus, Osher et al. (2018) underscore the protective importance of the development of positive relationships with parents, siblings, peers, caregivers, and teachers.

Cantor, Osher, and their co-authors present, then, the state-of-the art of developmental science as involving a dynamic, integrated, and whole-child view of youth development, and of the interconnectedness between an individual and his or her physical, social, and cultural contexts. Such scholarship offers a unique opportunity to study and positively influence each young person's developmental path across his or her life. Their ideas offer a rich set of opportunities for youth development practitioners to find and align the strengths of specific youth and the resources in the context of youth that, when combined across the course of participation in a specific youth program, can enhance thriving.

Together, the articles embody the frontier in which the study of youth development is now located: Contemporary scientific understanding of the dynamics of the developmental system opens pathways for new, creative research and applications. These new pathways for developmental scholarship have the potential to solve heretofore seemingly intractable problems of human development. For instance, how can a youth program leader find ways to promote the positive development of every young person in his or her program? The answer to this question is complex because it is typically the case that each participant enters a youth development program with a diverse history of challenges, diverse, needs, diverse skills, and diverse aspirations about the benefits of the program. The ideas presented in the articles by Cantor et al. (2018) and Osher, et al. (2018) provide youth development program leaders with a rationale for focusing on the specific pathways that led a specific young person to the program, the specific program and broader contextual resources that may be useful for a specific youth to prosper in the program, and therefore the diverse ways in which the program may positively impact the subsequent pathway travelled by a specific young person.

Simply, the articles help youth program leaders identify and attend to the important dimensions of individuality of a young person and the specific facets of the contexts of young people that may have influenced prior pathways and that will influence subsequent ones. As well, the articles help program leaders understand how the context of the programs they offer may increase the likelihood of young people following positive pathways into the future by, for example, creating positive youth $\Leftrightarrow$ program leader relations that enhance each young person's life skills (Lerner, 2004). 
In short, the synthesis of current knowledge about human development found in the Cantor et al. (2018) and the Osher et al. (2018) articles demonstrates the power and potential of developmental science to support positive adaptations, resilience, learning, health, and wellbeing for every young person. The articles also demonstrate the importance of theory in developmental science and, as well, of theory-predicated research to integratively enhance the lives of diverse young people. In contemporary developmental science, there is increasing emphasis placed on understanding how theories (models) of development are shaped by specific sets of philosophical ideas, termed metatheories (Overton, 2015). It is useful to discuss the metatheory that shapes dynamic developmental models.

\section{Relational Developmental Systems Metatheory}

A metatheory is a theory of theories. It is a philosophical statement about the specific concepts that should be included or excluded in theories (models of youth development, for instance) derived from a specific metatheory. For example, the writings of Rene Descartes (1641/1993) provide a metatheory that was used for devising scientific theories pertinent to human development through much of the $19^{\text {th }}$ and $20^{\text {th }}$ centuries (Overton, 2015). Cartesian metatheory promoted the development of theories that reduced phenomena to their purported essential elements (e.g., genes) (Overton, 2015). In doing so, these theories proposed splits between phenomena that were considered to be the fundamental causes of development (e.g., genes in nature theories, such as behavior genetics; e.g., Plomin, 2018) and phenomena of secondary or of no causal importance, for example, specific experiences in the family or encountering specific curricula within formal or informal educational settings (Overton, 2015).

In contrast to this perspective, contemporary developmental science focuses on theoretical models that are derived from relational developmental systems (RDS) metatheory (Overton, 2015). Table 1 defines the key concepts involved in RDS metatheory and in the philosophical paradigm from which it is derived. RDS metatheory emphasizes that processes associated with different levels of organization (e.g., biological, psychological, social, cultural, and historical) are integrated through mutually influential relations. 


\section{Table 1. Concepts Associated with Relational Developmental Systems Metatheory}

Activity. The biological, psychological, and social functions of a living organism across time and place.

Adaptive. Actions serving the maintenance and survival of an organism across time and place.

Coaction. The integration of the actions of a young person on his or her context (e.g., through contributions to the family, youth development program, or community) and the actions of the context on the youth (e.g., by mentoring, role modeling, or provision of social support).

Dynamic system. Mutually-influential actions across time and place of the components (variables) of an organized set of processes.

Holism. The inseparability of the components of an organism, process, or system.

Individual $\Leftrightarrow$ context relations. Mutually influential coactions across time between an individual and components of his or her context.

Levels of integration. The systematic coaction of variables or processes across time and place within the ecology of development, ranging from the molecular (e.g., genes) to the molar (e.g., social institutions, culture, and history [time]).

Living system. A dynamic and adaptive system.

Metatheory. A theory of theories. A philosophical statement about the specific concepts that should be included or excluded in theories derived from the metatheory.

Open system. A dynamic organization of processes that coacts with variables outside of (exogenous to) it.

Paradigm. A philosophical set of ideas about what exists (an ontology) and how what exists can be known (an epistemology).

Plasticity. The potential for systematic change in the development of an individual's characteristics.

Process-relational paradigm. A philosophical set of ideas stipulating that processes (systematic changes in components of a living system) are integrated dynamically and knowledge about these integrated processes can be obtained through understanding the bases and manifestations of these relations.

Self-construction (autopoiesis). The development of a system involves processes internal to the system; the construction of a system (e.g., human development) does not require resources outside of the system or entities (e.g., genes) or energies (e.g., evolution) existing prior to the emergence of a system for the system to be constructed.

Self-organization. A system (e.g., human development, a living system) can assemble itself; a selforganizing system does not need to receive assembly instructions from resources or energies outside of it.

Temporality. Time or history. 


\section{Theory-Predicated Research in Youth Development}

Models derived from RDS metatheory are at the cutting edge of developmental theories (Lerner, 2018). These models emphasize that fused, mutually-influential relations between nature and nurture (i.e., of biology and context, or biology $\Leftrightarrow$ context relations) constitute the fundamental process of youth development. For instance, in the theories of both Bronfenbrenner (e.g., Bronfenbrenner \& Morris, 2006) and Elder et al. (2015) biology, psychology, the social context, the physical ecology, and history (time) are all integrated in the ecology of human development. The conceptual emphasis in RDS-based theories is placed on mutually influential relations between individuals and contexts, which I have noted is represented as individual $\Leftrightarrow$ context relations.

Individual $\Leftrightarrow$ context relations vary across place (e.g., culture) and across time (e.g., periods of development of a person or the historical periods within which different birth cohorts of youth develop; Elder, et al., 2015). The "arrow of time," or temporality, is history, which is the broadest level within the ecology of human development. History imbues all other levels with change. Such change may be random (e.g., nonnormative life or historical events; Baltes, Lindenberger, \& Staudinger, 2006). Examples might be unanticipated environmental calamities, such as oil spills in the ocean, or accidents that damage the power grid for an area of the nation. Historical change may also be systematic (e.g., history- or age-graded changes). Examples are changing laws that provide suffrage to formerly disenfranchised groups, and age of entry into formal education, respectively. The potential for systematic change (for plasticity) constitutes a potential for enhancing youth development. Such plasticity is a fundamental strength of human development; it provides a basis for optimism that the course of development for all young people may be enhanced (Lerner, 1984, 2018).

This RDS perspective, and the evidence that supports it, mean that theories (models) that split processes or variables apart are conceptually flawed. For example, such flaws exist in claims that biology, in one form or another, for instance, evolution or genes, is the prime determinant of change. Despite evidence to the contrary, flawed claims about the role of biology in youth development have been made and continue to be made in reductionist models such as sociobiology (Freedman, 1979), behavior genetics (e.g., Plomin, 2018; Plomin, DeFries, Knopik, \& Neiderhiser, 2016), evolutionary psychology (Buss, 2015), evolutionary developmental psychology (e.g., Bjorklund, 2015, 2016; Bjorklund \& Ellis, 2005), or in relabeled variants of these positions, such as life history theory (e.g., Del Giudice, 2014, 2015). These reductionist models are also flawed in regard to the role of genes in evolution (e.g., Jablonka \& Lamb, 2005; Pigliucci \& Mueller, 2010; West-Eberhard, 2003; Woese, 2004) and human development (e.g., Joseph, 2015; Lerner \& Overton, 2017; Moore, 2015; Richardson, 2017). 
In turn, and as I have noted, the relational (and non-reductionist), dynamic approach to developmental theory taken by Cantor et al. (2018) and Osher et al. (2018) better explains how variables are integrated holistically to provide the bases of the specific pathway of change for every individual. These variables are associated with levels of organization ranging from the genetic and neuronal, through the cognitive, emotional, and behavioral components of individual functioning, to the social-relational, cultural, and historical domains of the ecology of human development. In other words, to enact good science about youth development, the dynamic systems approach to theory (and not genetic reductionist approaches) should frame research and applications to youth development programs. Simply put, good science requires good theory (Baltes, Reese, \& Nesselroade, 1977; Collins, 2006; Lerner, 2018).

Among the many reasons for the importance of good theory in science is that the choice of methods used in research should be based on the theory-derived questions asked by a researcher (Lerner, 2018). Dynamic systems theories promote the use of methods that are able to document changes in the specific individual $\Leftrightarrow$ context relations that are involved in individual trajectories across life. Therefore, testing models of development depicting such changes requires the use of methods suited for measuring and analyzing these changes.

\section{On the Frontiers of Developmental Methodology}

The concepts associated with the contemporary features of developmental methods, and key issues of methodology pertinent to these features of methodology, are presented in Table 2. Review of the components of this table point out an obvious methodological issue in assessing youth development. Developmenta/methods must be change sensitive. Indeed, because the study of youth development is the study of developmental change during this period, change sensitivity should be a defining feature of developmental methods. However, some of the concepts presented in Table 2 suggest that there may be a surprising lack of consensus among researchers about this point. Indeed, change-sensitive methods are often not used in the study of youth development. 


\section{Table 2. Concepts Associated With Change-Sensitive Developmental Methods}

Aggregation of individuals' developmental change. Combining information about two or more individuals' development through averaging or clustering.

Change-insensitive analyses. Methods of treating data that cannot identify change if it is present. Change-insensitive designs. Methods of collecting data (e.g., cross-sectional methods) that cannot identify change within an individual (or other unit of analysis).

Change-insensitive measures. Measures that cannot detect changes in a construct (e.g., personality, temperament, life skills, or character) if in fact change occurs.

Change-sensitive analyses. Methods of treating data that can identify change if it is present.

Change-sensitive designs. Methods of collecting data (e.g., longitudinal methods) that can identify change within an individual (or other unit of analysis).

Change-sensitive measures. Measures that can detect changes in a construct (e.g., personality, temperament, life skills, or character) if in fact change occurs.

Endogeneity. Attributes of individuals selected to be in a sample that may affect their scores on a variable. Such selection "effects" create bias in samples.

Ergodic theorems. Theorems in mathematics that provide the bases for using population statistics (e.g., averages, standard deviations) in studying samples of individuals.

Homogeneity (in ergodic theorems). An assumption within the ergodic theorems that all members of a sample are the same in regard to the course of the developmental process being measured.

Idiographic change. Change that is specific to a specific individual.

Idiographic Filter. A statistical method that enables individuals to have their own (idiographic) pattern of change but that can identify commonalities among individuals through specific aggregation procedures.

Interindividual differences. Differences between people (e.g., in their patterns of within-person change).

Intraindividual change. Within-person change.

Measurement invariance. The equivalence across, people, time and place, in the meaning of, and in the statistical properties of a measure of a specific construct (e.g., intelligence, personality, character). Non-ergodicity. The attributes of each person's developmental individuality that negate the use of population statistics (e.g., group averages) to characterize a person.

Person-centered research. Research that focuses on the changes that exist within a person. Robustness analyses. Analyses that ascertain if the findings existing for an overall group of participants continue to exist when the data set is divided into, say, boys versus girls or $6^{\text {th }}$ graders versus $7^{\text {th }}$ graders, etc. 
Table 2. Concepts Associated With Change-Sensitive Developmental Methods (continued)

Specificity principle. The universally applicable idea that human development involves specific changes in specific processes of a specific person developing at specific times in life, at specific points in history, and in relation to specific attributes of the contexts of the ecology of human development. Stationarity (in ergodic theorems). An assumption within the ergodic theorems that population statistics (the mean and standard deviation) remain unchanged in their applicability to the sample. Variable-centered research. Research that focus on the changes that exist for a variable (e.g., personality or character).

Variance partitioning. Dividing the variation in a data set into subsets linked to variables included in the data set (e.g., separating the variance associated with boys from the variance associated with girls, or separating the variance associated with $6^{\text {th }}$ grade youth from the variance associated with $7^{\text {th }}$ grade youth).

For instance, reviews of the contemporary research literature about the study of positive youth development (PYD) around the world (e.g., Lerner, Lerner, et al., 2018; Lerner, Tirrell, et al., 2018; YouthPower Learning, 2017) point to the relative lack of longitudinal studies or of longitudinal evaluations of youth development programs aimed at promoting PYD. Research design issues are one of the three facets of developmental methodology that should be discussed in regard to change sensitivity.

\section{The Design of Developmental Research}

Development involves intraindividual change (change within a person) and interindividual differences (differences between people) in within-person change (Baltes, et al., 1977; Lerner, 2018). For instance, all youth development programs seek to change for the better each participant's psychological or social characteristics. As well, youth development programs seek to diminish the gaps between participants in their positive characteristics. Youth development programs work to create a "rising tide" that "lifts" the development of all youth to more positive levels. Simply put, youth development programs aspire to be agents of positive change within each participant in the program. As well, youth development programs seek to diminish the differences between (a) participants who enter the program with less developed abilities or skills, and (b) participants who enter programs with better developed abilities and skills. As such, all developmental designs, whether aimed at generating basic, descriptive information about youth pathways across specific portions of childhood or adolescence or aimed at 
Theory-Predicated Research in Youth Development

evaluating the changing pathways youth travel over the course of program participation, require longitudinal (repeated) measurement (Collins, 2006; Nesselroade \& Baltes, 1979). However, it remains the case that many studies that are aimed at assessing facets of youth development use cross-sectional data (YouthPower Learning, 2017). Such data cannot be used to provide evidence of, or understanding about, within-person change.

The between-person differences that may be identified in cross-sectional research may not be due to between-person differences in within-person change (e.g., developmental change). These between-person differences may be due to variables that were not assessed (e.g., experiential differences among participants, for instance, in histories of participation in out-ofschool-time programs). As well, between-person differences may be due to variables that have not been analyzed although they may exist in the data set (e.g., religious variation, family structure variation, area of residence, or gender or race). This problem - of not being able to account for the basis of between-people differences in cross-sectional data sets-becomes especially important to recognize when the cross-sectional sample includes groups of different ages. The temptation to treat age-group differences as if they reflected age changes is often too powerful for researchers or practitioners to ignore.

However, the temptation should be ignored. If not ignored, then researchers and youth program leaders run the risk of believing they are changing the development of young people when, in fact, their evidence does not pertain to development-to within-individual change-in relation to program participation.

As well, research designs should include plans for assessment of endogeneity (sample selection effects) associated with different groups. For example, youth from high-income families are more likely to participate in specific youth activities (Eccles \& Gootman, 2002). Pre-existing differences among youth from high-income families may be responsible (or, perhaps, more responsible) for youth behavior and development rather than their participation in the program. Designs should also include plans to examine whether or not the findings that exist for an overall group of participants also exist when specific groups of participants, say, boys versus girls, are assessed separately. The overall finding may mask key differences for male and female youth within the group.

Duncan, Engel, Claessens, and Dowsett (2014) recommend assessing if the overall findings for a sample of youth are still present (what they term as remaining "robust") when assessed in regard to specific subgroups of the sample. For instance, if a program promoting PYD is 
Theory-Predicated Research in Youth Development

demonstrated to have a successful impact on a sample of participants, does the finding of program success hold for the boys and the girls in the sample or for the younger or older youth in the sample? If so, then the overall results may be termed robust findings (Duncan, et al., 2014). I return to issues of data analysis in a subsequent section. Here, however, I turn to issues pertinent to developmental measurement.

\section{Measuring Developmental Change}

All measures used in the study of within-person (intraindividual) change must be able to detect changes, if they exist, across the specific time divisions used in a specific study (Lerner, 2018), for example, weeks, months, or years. However, it is often the case that measures are specifically developed to be insensitive to variation across time or place-most notably, measures of purported personality traits (e.g., Costa \& McCrae, 1980; McCrae, et al., 2000).

Such measurement is both conceptually and empirically flawed. There may certainly be good reasons to create and use measures that are insensitive to variation across time and space. For example, devising a radiological measure of jaw bone loss in people of different ages and contextual (e.g., national) settings might be very important in the field of restorative dentistry. However, in the field of human development, wherein the fundamental questions are about changes in the processes of life, measures that are impervious to age- or context-associated variation are useless.

Therefore, in the development of developmentally-appropriate measures, assessment must be made of whether change can be detected across theoretically meaningful divisions of time (e.g., weeks or months for infant motor development or cognitive development, respectively; or years, for the development among youth of identity, romantic relationships, or vocational interests). For example, if researchers had a hypothesis that the transition from elementary school to middle school may change the self-esteem of adolescents (e.g., Simmons \& Blyth, 1987), then the researchers must use a measure that could detect changes across this period in order to test their hypothesis.

Most critically, change-sensitivity of measures of development must be identifiable at the individual level of analysis. As I have emphasized (see too Baltes, et al., 1977; Lerner, 2018), the study of development is the study of intraindividual change. Such within-the-person measures need to possess more than reliability or validity. They must also possess measurement invariance (equivalence) across times of measurement: Measures must have the 
Theory-Predicated Research in Youth Development

same meaning at different times of life and, as well, measures must have several statistical properties that assure equivalence of measurement (e.g., see Card, 2017, for a discussion of these statistical properties). Moreover, if measures are used in studies of groups of people across national settings, they must also possess invariance across people and places (Card, 2017).

In sum, then, developmentally useful measures must be invariant in regard to their statistical properties and they must also be able to address change, especially change specific to a specific individual. This point raises the issue of person-centered versus variable-centered data analyses in developmental science.

\section{The Analysis of Developmental Change}

In developmental science, statistical procedures aimed at the analysis of within-person changes should be aimed, first, at discovering how variables covary (change together) within a person across time. The aim of developmental science is to understand each person's individually distinct (idiographic) pathway. Therefore, analyses that focus on changes within a person (person-centered analyses) are essential starting points in developmental research. In turn, second, analyses can be aimed at determining if it is possible to group (aggregate) individuals in regard either to sub-samples of individuals (e.g., all boys in the study, or all 12 year-olds in the study) or to a sample as a whole (Molenaar \& Nesselroade, 2015).

However, at this writing, the predominant approach to creating evidence in support of the theoretical ideas about a developmental process (e.g., in regard such constructs as resilience, gender identity, or executive functioning) or of programs aimed at enhancing the scores of youth in regard to these variables is based on variable-centered assessments. That is, many developmental scientists continue to focus on how variables covary across individuals within points in time. Such analyses, even if computed at several successive times of measurement, reveal nothing about development. That is, such analyses say nothing about within-person change (Molenaar \& Nesselroade, 2014, 2015; Nesselroade \& Molenaar, 2010; Rose, 2016). In short, variable-centered analyses, although reflecting a common, indeed a standard, approach

to data analysis in the social and behavioral sciences (Molenaar, 2014), have no relevance to changes within an individual.

This standard approach to statistical analysis in the social and behavioral sciences is derived from specific mathematical assumptions (the ergodic theorems). These mathematical ideas 
allow specific statistical analyses (e.g., the computation of averages or standard deviations) that pertain to populations (e.g., to al/middle school youth) to be used in computing characteristics of a sample of youth from the population (e.g., a sample of 100 middle-school youth from a specific city in the U.S. who are participants in a specific program promoting PYD) (Molenaar, 2014). However, using statistics that are appropriate for populations with select samples from that population is only legitimate if a researcher can assume that every person in the sample is essentially the same (i.e., that they are homogeneous) and that the scores of each individual in the sample contribute to the sample average and standard deviation to the same extent across time (a situation termed stationarity).

For example, the 100 middle school youth in the above-noted sample would have to be considered essentially the same if their PYD scores are to be added together and then divided by 100 to obtain the average PYD score for the sample. However, it may be the case that some young people in the sample could not be considered the same. For example, if some youth had different cultural backgrounds and English-language abilities because they were recent immigrants to the United States, then they could not necessarily be considered the same as youth from the culture who were native speakers of English. Thus, the measure of PYD in the former group might not have measurement properties that were equivalent to the measurement properties of the PYD measure when used with the latter group. If so, then the measure of PYD would not be equivalent for the two groups, and the computation of an overall sample average (or standard deviation for that matter) would not be appropriate. In addition, as the immigrant youth became acculturated and as their English-language abilities increased, their PYD scores - and thus their "contribution" to the average score for the sample-would likely change. Therefore, the ergodic assumptions of homogeneity and stationarity would not hold for the sample in this example.

Simply, analysis of the characteristics of a sample through the use of the population statistics would not be appropriate if individuals were different at a specific point in their lives and if their differences followed diverse developmental courses across childhood and adolescence (Nesselroade \& Molenaar, 2010; Molenaar, 2014; Molenaar \& Nesselroade, 2014, 2015). As documented in the reviews of Cantor, et al. (2018) and Osher, et al. (2018), such individuality is the case in the study of youth development. Youth development is, then, non-ergodic. Therefore, researchers should not use statistical analyses (e.g., the computation of averages and standard deviations) that are reflections of an interest in populations if they are actually interested in individuals (Molenaar \& Nesselroade, 2015). 
As a consequence, to obtain valid information about developmental processes it is necessary to have the study of within-person change within single individuals as a primary focus of developmental analysis. Towards such analyses, Molenaar and Nesselroade (2015; Nesselroade \& Molenaar, 2010) have developed statistical procedures such as the Idiographic Filter. The Idiographic Filter recognizes that, although each person may have a specific (individual) course of development, individuals may nevertheless be aggregated if their individual pathways are sufficiently similar to allow groups to be formed. If such groups can be formed, then generalizations across people can be made. Through use of procedures such as the Idiographic Filter, developmental scientists may capture the unique features of within-person change and, as well, produce generalities about groups.

To indicate the research implications of this approach, it is important to understand the "specificity principle" (Bornstein, 2017). This principle involves researchers asking a multi-part "what" question when conducting programmatic research exploring the function, structure, and content of development of diverse youth. For instance, in seeking to understand how diverse youth may have a specific series of individual $\Leftrightarrow$ context relations associated with adaptive, healthy, or positive development, researchers might undertake programs of research framed by a multi-part question such as: "What features of positive development emerge; that are linked to what trajectory of individual $\Leftrightarrow$ context relations; for youth of what sets of individual psychological, behavioral, and demographic characteristics; living in what families, schools, faith communities, neighborhoods, nations, cultures, and physical ecologies; at what points in ontogenetic development; and at what historical periods?"

Accordingly, through conducting programmatic research addressing such specificity-based questions, the particular sets of individual $\Leftrightarrow$ context relations involved in the life of a specific youth may be identified and, as well, the specific relations associated with his or her healthy or positive development may be discovered (e.g., see Rose, 2016). Therefore, one key outcome of such specificity principle-framed research can be the identification of the diverse ways in which individual $\Leftrightarrow$ context relations may capitalize on the potential for plasticity in human life and result in adaptive, healthy, or positive development for all young people (Spencer, Swanson, \& Harpalani, 2015).

\section{Implications for Policy and Program Applications}

The innovations in theory and methodology I have discussed have important implications for applications to policies and programs. Arguably, the most significant implication of RDS 
Theory-Predicated Research in Youth Development

metatheory lies in the concept of plasticity. The potential for development to change systematically because of alterations in the relations between a young person and his or her context means that "what you see (at one point in a young person's life) is not what you (have to) get (settle for)." Practitioners can capitalize on a young person's plasticity and, by altering his or her relations with his or her settings, change the course of the development of the youth. Therefore, if policy makers invest more resources in programs that constitute evidence-based innovations in the ways that youth coact with peers and adults in school or out-of-school curricula, then they can be optimistic that youth development may be enhanced. Similarly, plasticity means that practitioners can be confident that, if they can use their knowledge to align the strengths of the youth in their programs with program features that enable these strengths to become practiced and to be enhanced, they can promote more positive development in each of their program participants.

The methodological innovations I have reviewed should be the foundation for new policies and for program features that enable the potential for plasticity to be actualized in support of positive development among diverse youth. First, there is a reason that innovations in research design were of concern to developmental methodologists. Programs cannot change the course of youth development overnight. Successful programs require that their resources be used with sufficient intensity and duration to effect change (Vandell, Larson, Mahoney, \& Watts, 2015). As such, policy makers need to invest in programs across periods of youth development sufficiently long for change to be detected. Of course, these periods will vary in length in relation to the specific facets of youth development that the program seeks to enhance.

For instance, learning new camping skills-for example, successfully pitching a tent, using the correct knots to securely stabilize the tent, and safely starting, monitoring, and killing a campfire-may be attained in weeks or months when taught by competent, experienced adult leaders. However, promoting features of character development or creating a growth mindset in youth with a fixed mindset may not be able to be accomplished in days, weeks, or even a few months. More extended programs will likely be necessary. Practitioners and researchers need to collaborate to inform policy makers about the specific lengths of time in which they need to invest for specific outcomes to be realized and, in turn, practitioners need to be certain that the theories of change associated with their programs recognize the time investments needed to actualize specific changes.

In addition, if evidence of program effectiveness is to be generated from the evaluations of practitioners' efforts, a key implication of the methodological innovations I have discussed is 
Theory-Predicated Research in Youth Development

that practitioners must use measures of outcomes that are sensitive to change. If a program outcome (e.g., enhanced camping skills) is expected to be realized in a few weeks, then measures of the new skills must be able to detect change within this time period. If monthly progress in the development of a growth mindset is assessed in order to monitor the ongoing progress of a program, then practitioners need to interrogate consultants, research partners, or evaluators about whether the measures of outcomes recommended for use have the sensitivity needed to detect change if it occurs.

Without use of such measures, the practitioner will not be able to generate evidence of program effectiveness and, as such, funders and policy makers will inevitably lose confidence in the quality of a program. The innovations in data analysis that I reviewed will be irrelevant if the data being analyzed come from measures that are not sensitive to change within and across the specific period of life in which the program is offered.

Finally, and arguably the most profound innovation in methodology I discussed is one derived from the theoretical ideas in RDS metatheory that emphasize the individuality and specificity of each young person's development. Policy makers and, as well, government and private funders, are often moved or, at least, intrigued by stories of an individual young person's success, especially if the success involves overcoming the odds that-because of adversity , racism, gender discrimination, or other instances of disparities of opportunity-failure was likely. Nevertheless, policy makers and funders allocate resources to change groups. As such, the major challenge derived from the methodological innovations I have discussed is to explain to the people in charge of resource allocation that program success should not be evaluated solely by looking at an average level of improvement. Evidence that the average score for a group experiencing a program has improved does not mean that every young person in the group has shown positive development equivalent to the average.

Policy makers and funders must be educated to ask for more nuanced information about program effects and, in turn, practitioners, armed with change-sensitive measures used across appropriate lengths of time for their program to work, must collect information about the specific pathways of change they have facilitated. Coupled with conventional information about group changes, practitioners can begin to be attuned to, and become more knowledgeable about, how specific facets of specific program are associated with specific outcomes for specific youth. 
Theory-Predicated Research in Youth Development

I believe knowledge of the specific outcomes for specific youth will enhance the ability of practitioners to successfully garner more resources for their efforts at enhancing the positive development of youth, especially when overall program effects are found to be small. When both policy makers and practitioners are aware of the individual specificity of each youth, then evidence of specific program effects, even in the face of small overall, group effects, will not be able to be ignored. They will be sought and, perhaps as well, be celebrated.

\section{Conclusions}

Holistic and integrated views of human development have been documented in theory-predicted research involving multiple disciplines (Cantor et al., 2018; Osher et al., 2018). This research continues to illuminate the specific features of the dynamic, individual $\Leftrightarrow$ context relations comprising the uniqueness of each person's journey across the life span. The growing knowledge of these individual pathways (e.g., Brose, Schmiedek, Lövdén, Molenaar, \& Lindenberger, 2010; Brose, Schmiedek, Lövdén, \& Lindenberger, 2012; Ram, et al. 2005) will continue to illuminate how applications of developmental science may enhance the positive development of every young person, no matter the adversity or challenges he or she may have encountered (Cantor et al., 2018; Osher et al., 2018). Enhancing the capacities of developmental scientists to continue to improve the life journeys of diverse youth of course rests on further achievements in theory and methodology.

However, I believe there is a clear pathway forward across the frontiers of theory and method that I have discussed. Idiographic-specificity-principle-framed research focusing on the diversity of youth development may be able to identify the specific individual $\Leftrightarrow$ context relations linked to overcoming adversity and thriving for specific youth or groups of youth, in specific communities, at specific times in the first decades of life. If so, then, developmental scientists could capitalize on the relative plasticity of youth development and assess if, by creating the conditions for such relations among other, similar youth, more general positive development could be promoted.

The current state of developmental science is one in which theory and methodology are finally catching up to one another (Lerner, 2012). Developmental scientists have theoretical and methodological ideas and tools to enhance their understanding of how researchers should collect and analyze data to generate evidence applicable at the individual level. Such evidence should be used for innovations in policy and practice that may promote lives of personal thriving and social contribution among the diverse young people of our world. 


\section{Acknowledgements}

The preparation of this paper was supported in part by grants from the John Templeton Foundation and the Templeton Religion Trust. I thank Dale Blyth, Edmond P. Bowers, Elizabeth Dowling, G. John Geldhof, Jonathan Tirrell, and Daniel Warren for their comments.

\section{References}

Baltes, P. B., Lindenberger, U., \& Staudinger, U. M. (2006). Life-span theory in developmental psychology. In R. M. Lerner (Volume Ed.), Handbook of child psychology: Vol. 1 Theoretical models of human development (6 $6^{\text {th }}$ ed., pp. 569-664). Editors-in-chief: William Damon and Richard M. Lerner. New York: Wiley.

Baltes, P. B., Reese, H. W., \& Nesselroade, J. R. (1977). Life-span developmental psychology: Introduction to research methods. Monterey, CA: Brooks/Cole.

Bjorklund, D. F. (2015). Developing adaptations. Developmental Review, 38, 13-35. doi:10.1016/j.dr.2015.07.002

Bjorklund, D. F. (2016). Prepared is not preformed: Commentary on Witherington and Lickliter. Human Development, 59, 235-241. doi:10.1159/000452289

Bjorklund, D. F., \& Ellis, B. J. (2005). Evolutionary psychology and child development: An emerging synthesis. In B. J. Ellis \& D. F. Bjorklund (Eds.), Origins of the social mind: Evolutionary psychology and child development (pp. 3-18). New York: Guilford.

Bornstein, M. H. (2017). The specificity principle in acculturation science. Perspectives in Psychological Science, 12(1), 3-45. doi:10.1177/1745691616655997

Bronfenbrenner, U. (Ed.). (2005). Making human beings human: Bioecological perspectives on human development. Thousand Oaks, CA: Sage.

Bronfenbrenner, U., \& Morris, P. A. (2006). The bioecological model of human development. In R. M. Lerner (Vol. Ed.), Handbook of child psychology: Vol. 1 Theoretical models of human development (6 ${ }^{\text {th }}$ ed., pp. 793-828). Editors-in-chief: W. Damon \& R. M. Lerner. Hoboken, NJ: Wiley.

Brose, A., Schmiedek, F., Lövdén, M., Molenaar, P. C. M., \& Lindenberger, U. (2010). Adult age differences in covariation of motivation and working memory performance: Contrasting betweenperson and within-person findings. Research in Human Development, 71 ), 61-78. doi:10.1080/15427600903578177

Brose, A., Schmiedek, F., Lövdén, M., \& Lindenberger, U. (2012). Daily variability in working memory is coupled with negative affect: The role of attention and motivation. Emotion, 12(3), 605-716. doi:10.1037/a0024436 
Buss, D. M. (Ed.). (2015). The handbook of evolutionary psychology, $2^{\text {nd }}$ ed. New York: Wiley.

Cantor, P., Osher, D., Berg, J., Steyer, L. \& Rose, T. (2018). Malleability, plasticity, and individuality: How children learn and develop in context. Applied Developmental Science. doi:10.1080/10888691.2017.1398649.

Card, N. A. (2017). Methodological issues in measuring the development of character. Journal of Character Education, 13(2), 29-45.

Cole, S. W. (2014). Human social genomics. PLOS Genetics, 10(8), 1-7. doi:10.1371/journal.pgen.1004601

Collins, L. M. (2006). Analysis of longitudinal data: The integration of theoretical model, temporal design, and statistical model. Annual Review of Psychology, 57, 505-528. doi:10.1146/annurev.psych.57.102904.190146

Costa, P. T., Jr., \& McCrae, R. R. (1980). Still stable after all these years: Personality as a key to some issues in adulthood and old age. In P. B. Baltes \& O. G. Brim, Jr. (Eds.), Life span development and behavior. Volume 3 (pp. 65-102). New York, NY: Academic Press.

Del Giudice, M. (2014). An evolutionary life history framework for psychopathology. Psychological Inquiry, 25, 261-300. doi:10.1080/1047840X.2014.884918

Del Giudice, M. (2015). Self-regulation in an evolutionary perspective. In G. H. E. Gendolla, M. Tops, \& S. Koole (Eds.), Handbook of behavioral approaches to self-regulation (pp. 25-42). New York: Springer.

Descartes, R. (1641/1993). Discourse on method; and, Meditations on first philosophy. Indianapolis, IN: Hackett.

Duncan, G. J., Engel, M., Classens, A., \& Dowsett, C. L. (2014). Replication and robustness in developmental research. Developmental Psychology, 50(11), 2417-2425. doi:10.1037/a0037996

Eccles, J. S., \& Gootman, J. A. (Eds.). (2002). Community programs to promote youth development. Washington, DC: National Academy Press.

Elder, G. H., Shanahan, M. J., \& Jennings, J. A. (2015). Human development in time and place. In M. H. Bornstein and T. Leventhal (Eds.), Handbook of child psychology and developmental science, vol. 4: Ecological settings and processes in developmental systems ( $7^{\text {th }}$ ed., pp. 6-54). Editor-in-chief: R. M. Lerner. Hoboken, NJ: Wiley.

Freedman, D. G. (1979). Human sociobiology: A holistic approach. New York, NY: Free Press.

Geldhof, G. J., Larsen, T., Urke, H., Holsen, I., Lewis, H., \& Tyler, C. P. (2019). Indicators of positive youth development can be maladaptive: The example case of caring. Journal of Adolescence, 71 , 1-9. doi:10.1016/j.adolescence.2018.11.008

Jablonka, E., \& Lamb, M. (2005). Evolution in Four Dimensions: Genetic, epigenetic, behavioral, and symbolic variation in the history of life. Cambridge, MA: MIT Press 
Theory-Predicated Research in Youth Development

Joseph, J. (2015). The trouble with twin studies: A reassessment of twin research in the social and behavioral sciences. New York, NY: Routledge.

Lerner, R. M. (1984). On the nature of human plasticity. New York: Cambridge University Press.

Lerner, R. M. (2004). Liberty: Thriving and civic engagement among America's youth. Thousand Oaks, CA: Sage.

Lerner, R. M. (2012). Essay review: Developmental science: Past, present, and future. International Journal of Developmental Science, 6(1-2), 29-36. doi:10.3233/DEV-2012-12102

Lerner, R. M. (2018). Concepts and theories of human development, $4^{\text {th }}$ ed. New York: Routledge. Lerner, R. M., Lerner, J. B., Geldhof, G. J., Gestsdóttir, S., King, P. E., Sim, A. T. R., . . Dowling, E. (2018). Studying positive youth development in different nations: Theoretical and methodological issues. In J. J. Lansford \& P. Banati (Eds.) Handbook of Adolescent Development Research and Its Impact on Global Policy (pp. 68-83). New York, NY: Oxford University Press.

Lerner, R. M., \& Overton, W. F. (2017). Reduction to absurdity: Why epigenetics invalidates all models involving genetic reduction. Human Development, 60(2-3), 107-123. doi:10.1159/000477995

Lerner, R. M., Tirrell, J. M., Dowling, E. M., Geldhof, J., Gestsdóttir, S., Lerner, J. V., . . Sim, A. T. R. (2018). The end of the beginning: Evidence and absences studying PYD in a global context. Adolescent Research Review. doi.org/10.1007/s40894-018-0093-4.

McCrae, R. R., Costa, P. T. Jr., Ostendorf, F., Angleitner, A., Hřebíčková, M., Avia, M. D., . . Smith, P. B. (2000). Nature over nurture: Temperament, personality, and life span development. Journal of Personality and Social Psychology, 78(1), 173-186. doi:10.1037/0022-3514.78.1.173

Molenaar, P. C. M. (2014). Dynamic models of biological pattern formation have surprising implications for understanding the epigenetics of development. Research in Human Development, 11, 50-62. doi:10.1080/15427609.2014.874765

Molenaar, P. C. M., \& Nesselroade, J. R. (2014). New trends in the inductive use of relation developmental systems theory: Ergodicity, nonstationarity, and heterogeneity. In P. C. Molenaar, R. M. Lerner, and K. M. Newell (Eds.), Handbook of Developmental Systems and Methodology. (pp. 442-462). New York, NY: Guilford Press.

Molenaar, P. C. M., \& Nesselroade, J. R. (2015). Systems methods for developmental research. In W. F. Overton, \& P. C. Molenaar (Eds.), Theory and method. Volume 1 of the handbook of child psychology and developmental science ( $7^{\text {th }}$ ed., pp. 652-682). Editor-in-chief: R. M. Lerner. Hoboken, NJ: Wiley.

Moore, D. S. (2015). The developing genome: An introduction to behavioral epigenetics. New York, NY: Oxford University Press.

Nesselroade, J. R., \& Baltes, P. B. (Eds.). (1979). Longitudinal research in the study of behavior and development. New York, NY: Academic Press. 
Nesselroade, J. R., \& Molenaar, P. C. M. (2010). Emphasizing intraindividual variability in the study of development over the life span. In W. F. Overton (Ed.), The handbook of life-span development. Vol. 1: Cognition, biology, methods (pp. 30-54). Editor-in-chief: R. M. Lerner. Hoboken: Wiley.

Osher, D., Cantor, P., Berg, J., Steyer, L. \& Rose, T. (2018). Drivers of human development: How relationships and context shape learning and development. Applied Developmental Science. doi:10.1080/10888691.2017.1398650.

Overton, W. F. (2015). Process and relational developmental systems. In W. F. Overton \& P. C. M. Molenaar (Eds.), Handbook of Child Psychology and Developmental Science, Volume 1: Theory and Method (7 ${ }^{\text {th }}$ ed., pp. 9-62). Editor-in-chief: R. M. Lerner. Hoboken, NJ: Wiley.

Pigliucci, M., \& Mueller, G. B. (2010). Elements of an extended evolutionary synthesis. In M. Pigliucci \& G. B. Mueller (Eds.), Evolution - The extended synthesis (pp. 3-17). Cambridge, MA: MIT Press.

Plomin, R. (2018). Blueprint: How DNA makes us who we are. London, UK: Allen Lane.

Plomin, R., Defries, J. C., Knopik, \& J. M. Neiderhiser, J. M. (2016). Top 10 replicated findings from behavioral genetics. Perspectives on Psychological Science, 11(1), 3-23. doi:10.1177/1745691615617439

Ram, N., Chow, S. M., Bowles, R. P., Wang, L., Grimm, K., Fujita, F., \& Nesselroade, J. R. (2005). Examining interindividual differences in cyclicity of pleasant and unpleasant affect using spectral analysis and item response modeling. Psychometrika, 70, 773-790. doi:10.1007/s11336-0011270-5

Richardson, K. (2017), Genes, brains and human potential: The science and ideology of human intelligence. New York, NY: Columbia University Press.

Rose, T. (2016). The end of average: How we succeed in a world that values sameness. New York, NY: HarperCollins.

Simmons, R. G., \& Blyth, D. A. (1987). Moving into adolescence: The impact of pubertal change and school context. New York, NY: Aldine De Gruyter.

Slavich, G. M., \& Cole, S. W. (2013). The emerging field of human social genomics. Clinical Psychological Science, 1, 331-348. doi:10.1177/2167702613478594

Spencer, M. B., Swanson, D. P., \& Harpalani, V. (2015). Development of the self. In M. E. Lamb (Volume Ed.), Handbook of child psychology and developmental science, Volume 3: Socioemotional processes (7th ed., pp. 750-793). Editor-in-Chief: R. M. Lerner. Hoboken, NJ: Wiley.

Vandell, D. L., Larson, R. W., Mahoney, J. L., \& Watts, T. W. (2015). Children's organized activities. In M. H. Bornstein \& T. Leventhal (Volume Eds.), Handbook of child psychology and developmental science, Volume 4: Ecological settings and processes ( $7^{\text {th }}$ ed., pp. 305-344). Editor-in-Chief: R. M. Lerner. Hoboken, NJ: Wiley.

West-Eberhard, M. J. (2003). Developmental plasticity and evolution. New York, NY: Oxford University Press. 
Journal of Youth Development | http://jyd.pitt.edu/ | Vol. 14 Issue 1 DOI 10.5195/jyd.2019.739

Theory-Predicated Research in Youth Development

Woese, C. R. (2004). A new biology for a new century. Microbiology and Molecular Biology Reviews, 68(2), 173-186. doi:10.1128/MMBR.68.2.173-186.2004

YouthPower Learning. (2017). A systematic review of positive youth development programs in low- and middle-income countries. Washington, DC: Making Cents International. 